\title{
Prospect of Tele-Pharmacists in Covid-19 Pandemic Situation in Bangladesh
}

Abdul Kader Mohiuddin

Department of Pharmacy Secretary and Treasurer Dr. M. Nasirullah Memorial Trust Tejgaon Bangladesh

"Correspondence author
Abdul Kader Mohiuddin
Department of Pharmacy
Secretary and Treasurer
Dr. M. Nasirullah Memorial Trust
Tejgaon
Bangladesh
Submitted: 05 May 2020 ; Published : 4 May 2020

\begin{abstract}
Telemedicine and telehealth technologies are especially effective during epidemic outbreaks, when health authorities recommend implementing social distance systems. Currently, coronavirus COVID-19 has affected 210 countries around the world, killed more than 240,000 and infected more than 3.4 million, according to worldometer, 03 May, 2020. Home-care is especially important in these situations because hospitals are not seemingly safe during pandemic outbreaks. Also, the chance to get out of the home during the lockdown period is limited. Telephone-based measures improve efficiency by linking appropriate information and feedback. It can also help provide education at distance on various health issues and topics. In addition to increasing access to healthcare, telemedicine is a fruitful and proactive way to provide a variety of benefits to patients seeking healthcare; diagnose and monitor critical and chronic health conditions; improve healthcare quality and reduce costs. The article reveals scope of pharmacy professionals in telemedicine sector during epidemic outbreaks.
\end{abstract}

\section{Introduction}

Bangladesh's health care services are becoming unusually concentrated in a small fraction of costly critical healthdemanding patients. A large part of these complex-patients suffers from multiple chronic diseases and are spending a lot of money. Tele-pharmacy includes patient counselling, medication review and prescription review by a qualified pharmacist for the patients who are located at a far distance from the pharmacy. The most common way to use telemedicine is a responsive model, primarily physician-led with virtual visits stimulated by alerts using interactive services, which facilitates real-time interaction between the patient and provider [1]. It delivers resilience to services and enables pharmacists to work remotely, reducing the need for long journeys and increasing job satisfaction [2]. The rise of pharmacists in epidemic situations has become increasingly popular in developed countries such as the United States, Australia, Canada and the United Kingdom. Along with doctors, pharmacists can serve as frontline healthcare workers during epidemics. The profession is developed and highly praised in both developed and underdeveloped countries. Millions of professional pharmacists worldwide work in various organizations, and according to data from the International Pharmaceutical
Federation (FIP), nearly $75 \%$ of them work in patient care [3]. Even in the United States, the continued lacking of primary health providers and medical specialists has made it possible for pharmacists to care for ambulatory patients with chronic diseases in a variety of treatment services [4]. This study contributes to the existing literature by describing eligibility of pharmacists in telemedicine for pandemic pharmacy services, which are currently nonexistent in Bangladesh.

\section{Methodology}

Research conducted a comprehensive month-long literature search, which included technical newsletters, newspapers and many other sources. This study started in February 2020, when the Philippines reported its first death outside China. PubMed, ALTAVISTA, Embase, Scopus, the Science Web and the Cochrane Central Register have been carefully searched. The keywords were used to search out extensively followed journals from various publishers such as Elsevier, Springer, Willey Online Library, and Wolters Kluwer. Medical and technical experts, pharmacy professionals, hospital staffs and journalists have given valuable suggestions. Projections 
were based on review of tele-pharmacists in both general and pandemic health situations, eligibility of pharmacists in telemedicine in general, present under-utilization scenario of Bangladeshi pharmacists in health services as well as in telemedicine sector. Major infrastructure revolution in both pharmacy education and country's technological advancement are necessary to build an effective telemedicine system in this country.

\section{Present Socio-Economic and Healthcare Situation}

Bangladesh is the seventh most populous country in the world and population of the country is expected to be nearly double by 2050 [6], where communicable diseases are a major cause of death and disability [7]. A recent Dengue outbreak in 2019, more than 100,000 people was affected in more than 50 districts in Bangladesh in the first 6 months of 2019 [8,9]. According to World Bank's Country Environmental Analysis (CEA) 2018 report, air pollution lead to deaths of 46,000 people in yearly in Bangladesh [10]. Although a riverine country, 65\% of the population in Bangladesh do not have access to clean water [11]. Both surface water and groundwater sources are contaminated with different contaminants like toxic trace metals, coliforms as well as other organic and inorganic pollutants [5]. Studies in capital Dhaka and Khulna also found that about $80 \%$ of fecal sludge from on-site pit latrines is not safely managed [12]. Nearly half of all slum dwellers of the country live in Dhaka division [13] and 35\% of Dhaka's population are thought to live in slums [14]. A recent research demonstrates widespread poor hygiene and food-handling practices in restaurants and among food vendors [15]. Less than $10 \%$ hospitals of this country follow the Medical Waste Management Policies [16]. In 2017, 26 incidents of disease outbreak were investigated by National Rapid Response Team (NRRT) of IEDCR [17]. Economic development and academic flourishment do not represent development in health sector. Out of the pocket treatment cost raised nearly $70 \%$ in the last decade [18]. Although, officially $80 \%$ of population has access to affordable essential drugs, there is plenty of evidence of a scarcity of essential drugs in government healthcare facilities [19]. Surprisingly, the country's pharmaceutical sector is flourishing, exports grew by more than $7 \%$ in last 8 months although total export earnings of the country drop to nearly $5 \%$ [20]. It has been found in Bangladesh that more than $80 \%$ of the population seeks care from untrained or poorly trained village doctors and drug shop retailers [21]. According to $\mathrm{WHO}$, the current doctor-patient ratio in Bangladesh is only 5.26 to 10,000 that places the country at second position from the bottom, among the South Asian countries [22]. According to World Bank data, Bangladesh has 8 hospital beds for every 10,000 people; by way of comparison, the US has 29 while China has 42 [23]. Tobacco is responsible for 1 in 5 deaths in Bangladesh, according to the WHO, kills more than 161,000 people on average every year. Around $85 \%$ population of age group 25-65 never checks for diabetes [24]. Joint survey of the Power and Participation Research Centre and BRAC Institute of Governance and Development (PPRC-BIGD Rapid Response Survey) reveals that per capita daily income of urban slum and rural poor by drops by $80 \%$, due to present countrywide shutdown enforced by the government to halt the spread of Covid-19. $40 \%$ to $50 \%$ of these population took loans to meet the daily expenses [25].

\section{Pharmacy Education in Bangladesh}

In many developing countries, including Bangladesh, pharmacy education is still limited to didactic learning which produces theoretically 'skilled' graduate professionals. Bangladesh's pharmacy curriculum doesn't really meet the minimum requirement for adequate clinical, hospital and community pharmacy education, as it is still linked to an old pharmacy model e.g. based on chemistry and basic sciences. That is present curriculum produces Pharmacist only to work in the pharmaceutical industry and jobs in this field of work is going to be saturated. No university so far have modified their curriculum including topics as epidemiology, pharmacoeconomics, clinical medicines, community skills. Manpower development for community pharmacies in Bangladesh is not systematically regulated and constitute an important public health issue. Three levels of pharmacy education are currently offered in Bangladesh leading to either a university degree, a diploma or a certificate. Graduates with degrees work in industry while those with diplomas work in hospitals [26]. Pharmacy is taught in about 100 public and private universities in Bangladesh and about 8000 pharmacy students graduate every year [27]. Due to a lack of government policy, hospital, community, and clinical pharmacy in Bangladesh were not well developed [28]. In real Bangladesh pharmacy practice areas for graduate pharmacists in industry i.e. industrial pharmacy practices, in marketing or regulatory sections are limited. The educational system of pharmacy is one of the major reasons for bounded pharmacy practices because the courses included in bachelor degree principally emphasize on industrial practices [29]. Over $90 \%$ of B. Pharm curriculum emphasizes on product-oriented knowledge whereas only around $5 \%$ of the total course credits are allocated toward clinical pharmacy. This curricular framework indicates a minimum emphasis on patient care education [30]. However, the graduates who pass out do not get employment easily due to their inadequate training, lack of thorough knowledge of fundamental concepts and practical skills [17]. Accordingly, qualified graduates leave for overseas where they are offered more prosperous jobs. Researchers argued that pharmacy education in Bangladesh can contribute to public and private benefits if its process determines a realistic pattern [31]. This system could be more beneficial to the public if the excellent hospital and community practices are introduced properly and also by involving the pharma professionals e.g. pharmacists and other skilled health care providers.

\section{Present State of Pandemic Situation Handling by} Bangladeshi Hospitals

More than $70 \%$ of the 7667 coronavirus cases detected in Bangladesh (as on 01, May, 2020) have been reported in Dhaka division and half of them are in capital Dhaka [32]. The virus hit a total of 11 out of the 64 districts in the country until 05.04.2020 after the first known cases were reported around a month ago, according to the government's disease control 
agency IEDCR [33]. Amidst this global crisis, Bangladesh has been identified as one of the 25 most vulnerable countries to be affected by the fast-spreading virus. From $1^{\text {st }}$ April to $14^{\text {th }}$ (IEDCR update until 19.04.2020 is shown in figure 1), Covid-19 cases became 20 -fold and by 30.04. 2020, it was confirmed in 63 out of 64 districts, taking the officially Covid- 19 death toll to $168[34,35]$. Many patients with fever, cold and breathing problems - which are also COVID-19 symptoms have gone untreated as the hospitals in Dhaka are sending them to the IEDCR for coronavirus test [36]. Many doctors are not providing services fearing the contagion and lab technicians are shunning workplaces halting medical tests, according to the patients. In some cases, serious patients who are not affected by COVID-19, moved from one hospital to the other but could not receive treatment and finally died, the media reported. In another case, the doctor fled leaving the patient behind [3740]. Doctors and other healthcare workers say they do not have adequate personal protective equipment and the health system cannot cope with the outbreak [41]. Police have locked down a total 52 areas of Dhaka after Covid-19 positive patients were found in the localities [42]. Experts say elderly people infected with coronavirus need ICU support the most. The number of older persons in the country is over 0.8 million [43]. In reality, hospitals in Bangladesh have less than 1200 ICU beds (432 govt, 737 private) in total against a population of 161.4 million people [44]. The health minister on 29.03.2020 reported that there are only 500 ventilators in the country [45].

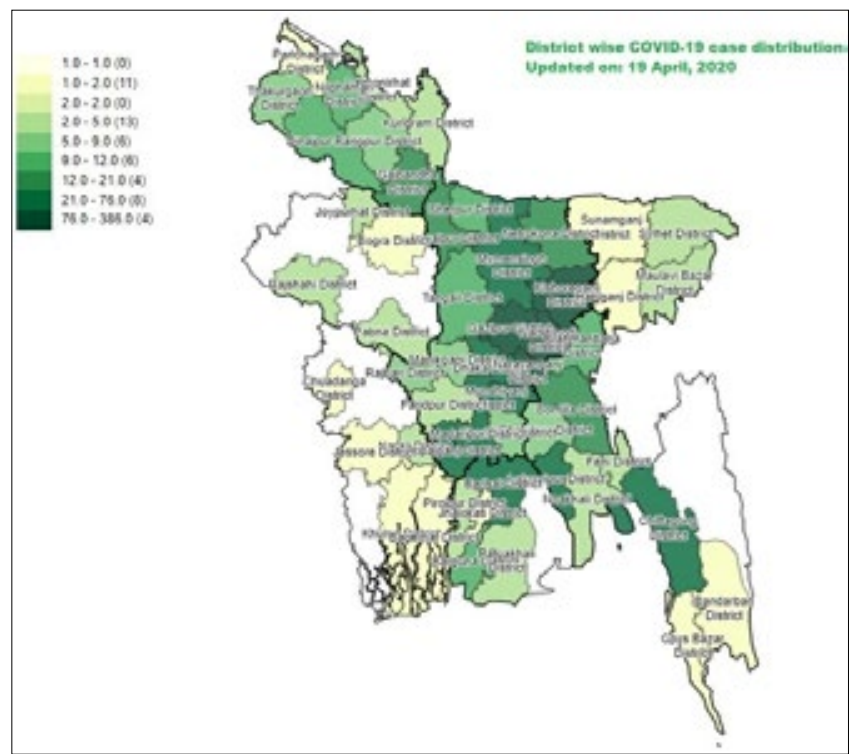

Figure 1: The Mapping of COVID-19 Confirmed Cases in BANGLADESH, 19 April 2020 (Source: IEDCR Web).

\section{Underutilization of Hospital Pharmacy}

Compared with developed countries, the pharmacy profession is still lagging behind in developing countries in a way that the pharmacy professionals have never been seen as part of the health care team either by the community or by the health care providers. Though hospital pharmacists are recognized in many developed nations for their importance as a healthcare professional, in most developing countries it is still underutilized or underestimated [45-48]. Hospital pharmacy practice has just begun in some modern private hospitals in
Bangladesh, which are inaccessible to most people because of the high cost of these hospitals to patients [49]. People are totally unknown to the responsibilities of hospital pharmacist, even they don't seek for recruit for hospital pharmacist in any hospital except a few aristocrat hospitals [50]. A Dhaka survey found nearly $50 \%$ of the respondents with acute respiratory disease (ARI) symptoms identified local pharmacies as their first point of care. Licenses are provided by the DirectorateGeneral of Drug Administration to drug sellers when they have completed a grade $\mathrm{C}$ pharmacy degree (i.e. 3 month course) for the legal dispensation of drugs [51] but a grade A pharmacy degree holder, having a B. Pharm or Pharm. D degree should be more equipped to handle these situations, if trained properly. Pharmacist's knowledge and helpfulness were identified as two key determinants which could not only satisfy and promote willingness to pay for the service [52]. They can individualize the medications and their dosing according to the needs of the patient, which can minimize the cost of care for the medication. In Bangladesh, however, graduate pharmacists do not engage directly in-patient care. Here, pharmacies in hospitals are primarily run by non-clinically educated, diploma pharmacists [28]. If the hospital pharmacy is established, patient care, proper dispensing of medications, and other patient-oriented issues can be handled properly. By maintaining a hospital pharmacy quality control program, the health sector can be enriched.

Prospect of Pharmacists in Patient Management Service and Telehealth Care

Pharmacists are the third largest healthcare professional group in the world after physicians and nurses [53]. At present, Hospital Pharmacy has created enormous job opportunities, where graduate pharmacists play a vital role in patient rearing, rehabilitation and wellness. A professional pharmacist at a clinic, hospital and community care can determine what to do in a given disease situation, preventing and counteracting any situation of health danger, ensuring high quality healthcare to seafarers all over the world [54-56]. The country has a huge opportunity to recruit these pharmacists at Telehealth Care. In each call, a pharmacist can provide both appropriate and quality information from the most recent medical systems. Studies show that the lack of proper medication management leads to higher healthcare costs, longer hospital stays, morbidity and mortality. Further, it was reported that one in every five hospitalizations was related to post-discharge complications and about seventy percent were related to proper use of the drug. In 2017, the World Health Organization committed to minimizing serious, avoidable drug-related harm over the next 5 years. Pharmacists' interventions to prevent drug-related problems at three community hospitals in California saved approximately 0.8 million USD in a year [57]. The estimated annual cost of medication error-based illnesses and deaths worldwide was USD 500 billion due to non-compliance with the clinical intervention and quantities in 2016. Also, the authors estimate that more than 275,000 people die every year for the same reasons [58]. A pharmacist can use simple and non-medical terminology to set the goal for patients to understand the information as well as to fulfill 
the prescription by proper request. With chronic conditions such as cardiovascular and respiratory diseases, there is ample evidence of the effectiveness of the tele-pharmacist for remote monitoring, communication and consultation [59]. In addition, psychotherapy can also be operated through telehealth as part of behavioral health [60]. The pharmacy-related needs of pandemic patients have similarities with the traditional patient population, but with different emphasis [61]. For example, when providing consulting services to patients, instead of focusing on medications as usual, their queries relate primarily to the knowledge of medical prevention and basic details on COVID-19, such as mask selection and standard COVID-19 signs and symptoms, symptomatic treatment options, breathing difficulties or cough management in comorbid situations, reinforcing behaviors that limit the spread of the pandemic, including social distancing and remaining in the home whenever possible through phone calls/video conferencing $[62,63]$. Earlier, Student pharmacists served as an effective education resource for patients regarding the $\mathrm{H} 1 \mathrm{~N} 1$ pandemic [64]. Sorwar et al, 2016 revealed that the existing telemedicine service reduced cost and travel time on average by $56 \%$ and $94 \%$ respectively compared to its counterpart conventional approach with high consumer satisfaction [65].

\section{History of Telehealth Service in Bangladesh}

The year 1998 represents a milestone for eHealth in Bangladesh when the first eHealth project was introduced by Swinfen Charitable, a non-profit institution. It associated collaborative work between the Center for Paralyzed Rehabilitation (CRP) in Bangladesh and Haslar Royal Navy Hospital in the UK. In the same year the Ministry of Health and Family Welfare (MoHFW) launched its first initiative on eHealth [66,67]. Just a year afterward the private enterprise Telemedicine Reference Center Limited (TRCL) started providing healthcare with mobile phones. The Bangladesh Telemedicine Association (BTA), a professional coalition, was created in 2001. That has provided a platform for ongoing and sparse eHealth initiatives in the country. A similar platform, called the Sustainable Development Network Program (SDNP), was formed in 2003 with the aim of establishing better cooperation and understanding between providers [68]. Later in 2006, TRCL paired with GrameenPhone (GP) and established the Health Line:789 subscriber mobile help desk [69,70]. A number of NGOs subsequently developed an interest in eHealth and mHealth, including BRAC, the Sajida Foundation and DNet [71]. In addition, Bangladesh launched a toll-free national emergency aid line 999 in December 2017 to meet immediate needs in the event of any accident, crime, fire or ambulance [72]. In addition, the IEDCR has launched 17 hotline numbers for the said Covid-19 outbreak [73].

\section{Challenges of Tele-pharmacy Implementation}

Firstly, it has limited evidence of its effectiveness beyond that of intervention by a traditional pharmacist. This favors the skepticism of both physicians and patients towards these services and limits their acceptance in the community [74]. Second, the tele-pharmacy is a service based on the technology. Thus, the driver is technology but also the limiting factor for its implementation. Establishing a tele-pharmacy service involves not only meeting technological requirements but also a considerable amount of time, effort and money [75]. Third, effective tele-pharmacy services should be based on standardized healthcare delivery models, and require appropriate regulations that may differ from country to country. For example, such facilities are not permitted or even restricted in some countries, while adequate legislation is available in others such as USA, Italy and other European countries [7679]. Unfortunately, despite the rampant potential of telepharmacy in many countries, the laws and policies governing pharmacy operations do not adequately address the growing sector. Fourthly, the reluctance or inability to use advanced technologies can limit the implementation of tele-pharmacy services from the perspective of both pharmacists and patients, especially in the context of the elderly [80-85]. Fifthly, since tele-pharmacy involves the gathering, transmission and replacement of personal and health information on the web, information security and privacy are major issues. Data sharing of information collected via tele-pharmacy services with other healthcare professionals increases the possibility of security breaches. The security and integrity of patient data is therefore of paramount importance when determining the setup of a tele-pharmacy system of information technology [86-91]. Sixth, the integration of tele-pharmacy services in the national healthcare systems and the connection of tele-pharmacy services (including a combination of electronic data entry, prescription order verification, online benefit adjudication, medication dispensing) among different areas of a country requires harmonizing the healthcare systems and related governing laws and setting up proper rules and regulations [9294]. Seventh, tele-pharmacy services are not yet reimbursed: individuals are required to pay for these services, and the expenses are not covered by private or public health insurance [95-99]. This restricts the use of these services by patients who may eventually need them.

\section{Overcoming Challenges}

In Bangladesh a number of telemedicine systems were introduced. Telemedicine laws and reimbursement policies since telemedicine practice is increasing on a daily basis in Bangladesh, so structured laws and regulations on doctors, patient issues, licensing of physicians and telemedicine providers are very much needed. Clear rules should be in place on questions of reimbursement. Bangladesh Television (BTV) and other satellite channels can play an important part in popularizing telemedicine. They should broadcast successful cases considering telemedicine's efficacy and costefficiency. Telemedicine systems and services compatibility of hardware and software require users to have compatible hardware at both ends of the communications link, which reduces interoperability and the benefits of access to different sources of telemedicine expertise. If the equipment is difficult to access or are less likely to involve practitioners. Equipment for wireless telemedicine is preferable to wire devices. Telemedicine privacy and confidentiality involves the electronic transmission of patient medical records and information from one location to another via the Internet, 
or other computerized media. Medical information is often delicate, confidential and private. Telemedicine, thus presents significant challenges for safeguarding the privacy and confidentiality of information about patient health. Specific privacy regulations should govern the practice of telemedicine so that patients can feel safe in knowing that confidentiality of their personal information will have to suffer certain penalties.

\section{Conclusion}

Overburdened by patient loads and the explosion of new drugs, physicians have increasingly turned to pharmacists for information about drugs, particularly within institutional settings. They acquire medical and medicinal history, check medication errors including prescription, dispensing and administration errors, identify drug interactions, monitor ADR, suggest dosage regimen individualization, provide patient counseling, etc. Among chronic disease patients, particularly those under quarantine, there is a greater challenge in the supply of drugs and compliance with medications, although the safety and effectiveness of care is still critical for these patients. Stronger data on the effectiveness of this area of pharmacy care, together with a critical assessment of its limitations, can raise awareness among the actors involved about its potential and could contribute to a wider dissemination of tele-pharmacy services in public interest. At the end, it can be said that pharmacists can play a role in both medical aids and regulation. But their social acceptance as a frontline patient care provider is necessary first. Similarly, in tele-healthcare, the professional pharmacist can play an essential role that has not been recognized yet due to lack of proper initiatives. We hope that policy makers of Bangladesh are aware of its potential and contribute to the wider promotion of tele-pharmacy services in the interest of the citizenry.

\section{Abbreviations}

IEDCR-Institute of Epidemiology, Disease Control and Research

\section{Acknowledgement}

I'm thankful to Dr. Mohammed A Mamun, Department of Public Health \& Informatics, Jahangirnagar University, for his precious time to review my literature and thoughtful suggestions. Also, I'm also grateful to seminar library of Faculty of Pharmacy, University of Dhaka and BANSDOC Library, Bangladesh for providing me books, journal and newsletters.

Financial Disclosure or Funding: N/A

Conflict of Interest: The author declares that he has no competing interests.

Informed Consent: N/A

Author contributions: N/A

\section{References}

1. Kane-Gill SL, Niznik JD, Kellum JA, et al. (2017) Use of Telemedicine to Enhance Pharmacist Services in the Nursing Facility. Consult Pharm 32(2): 93-98. doi:10.4140/TCP.n.2017.93.

2. Pike H. Web therapy: how pharmacists are leading the way on telehealth. The Pharmaceutical Journal 09.08.2018.

3. Bates I, John C, Bruno A, Fu P, Aliabadi S (2016) An analysis of the global pharmacy workforce capacity. Hum Resour Health 14(1): 61. Published 2016 Oct 10. doi:10.1186/s12960-016-0158-z

4. Goode JV, Owen J, Page A, Gatewood S (2019) Community-Based Pharmacy Practice Innovation and the Role of the Community-Based Pharmacist Practitioner in the United States. Pharmacy (Basel) 7(3): 106. Published 2019 Aug 4. doi:10.3390/pharmacy7030106

5. Hasan MK, Shahriar A, Jim KU (2019) Water pollution in Bangladesh and its impact on public health. Heliyon 5(8): e02145. Published 2019 Aug 2. doi:10.1016/j. heliyon.2019.e02145

6. Saha S, Hossain MT (2017) Evaluation of medicines dispensing pattern of private pharmacies in Rajshahi, Bangladesh. BMC Health Serv Res 17(1): 136. Published 2017 Feb 13. doi:10.1186/s12913-017-2072-Z

7. Muhammad F, Chowdhury M, Arifuzzaman M, Chowdhury AA (2017) Public Health Problems in Bangladesh: Issues and challenges. South East Asia Journal of Public Health6(2): 11-16. doi:10.3329/seajph. v6i2.31830.

8. Dayaram S, Pokharel S (2019) Bangladesh hit by worst dengue outbreak on record. CNNhealth July 30, 2019.

9. MohiuddinAK. Dengue Epidemic Situation in Bangladesh. Journal of Clinical Case Studies 4(3). doi:10.16966/24714925.193.

10. Mohiuddin AK (2019) Chemical Contaminants and Pollutants in the Measurable Life of Dhaka City. European Journal of Sustainable Development Research 3(2), em0083. https://doi.org/10.29333/ejosdr/5727

11. BBS/UNICEF (2018) Bangladesh MICS 2012-2013 Water Quality Thematic Report, March, 2018.

12. Amin N, Rahman M, Raj S, et al. (2019) Quantitative assessment of fecal contamination in multiple environmental sample types in urban communities in Dhaka, Bangladesh using SaniPath microbial approach. PLoS One 14(12): e0221193. Published 2019 Dec 16. doi:10.1371/journal.pone.0221193

13. Al-Shoaibi AAA, Matsuyama A, Khalequzzaman M, et al. (2018) Perceptions and behavior related to noncommunicable diseases among slum dwellers in a rapidly urbanizing city, Dhaka, Bangladesh: a qualitative study. Nagoya J Med Sci 80(4): 559-569. doi:10.18999/ nagjms.80.4.559

14. Van der Heijden J, Gray N, Stringer B, et al. (2019) 'Working to stay healthy', health-seeking behaviour in Bangladesh's urban slums: a qualitative study. BMC Public Health 19(1): 600. Published 2019 May 17. doi:10.1186/ s12889-019-6750-0 
15. Nizame FA, Alam MU, Masud AA, Shoab AK, Opel A, Islam MK, Luby SP, Unicomb L (2019) Hygiene in Restaurants and among Street Food Vendors in Bangladesh. Am J Trop Med Hyg 101(3): 566-575. doi: 10.4269/ajtmh.18-0896.

16. AK Mohiuddin (2018) Medical Waste: A Nobody's Responsibility After Disposal. Int J Environ Sci Nat Res 15(2): 555908. DOI:10.19080/IJESNR.2018.15.555908

17. Mohiuddin A (2019) An A-Z Pharmaceutical Industry: Bangladesh Perspective. Asian Journal of Research in Pharmaceutical Science 9(1): 17-28. doi:10.5958/22315659.2019.00004.3.

18. Mohiuddin AK (2019) Pharmaco-economics: Essential but merely practiced in Bangladesh. Academia Journal of Scientific Research 7(3): 182-187. DOI: 10.15413/ ajsr.2018.0195

19. Husain M, Rahman M, Alamgir A, Uzzaman MS, Flora MS (2019) Disease Surveillance System of Bangladesh: Combating Public Health Emergencies. Online J Public Health Inform 11(1): e334. Published 2019 May 30. doi:10.5210/ojphi.v11i1.9815

20. Online Report (2020) Export earnings drop to $\$ 26.24 \mathrm{~b}$ in eight months. The Financial Express, March 05, 2020.

21. Ahmed SM, Naher N, Hossain T, Rawal LB (2017) Exploring the status of retail private drug shops in Bangladesh and action points for developing an accredited drug shop model: a facility based cross-sectional study. J Pharm Policy Pract 10: 21. Published 2017 Jul 11. doi:10.1186/s40545-017-0108-8

22. Mohiuddin AK (2020) Patient satisfaction with healthcare services: Bangladesh perspective. International Journal of Public Health Science (IJPHS). 2020;9(1):34-45. doi:10.11591/ijphs.v9i1.20386.

23. Saleh A (2020) In Bangladesh, COVID-19 threatens to cause a humanitarian crisis. World economic Forum, 06.04.2020.

24. Mohiuddin AK (2019) TRACK (by NEHEP) Implementation: A Bangladesh Scenario. Pharmacovigilance and Pharmacoepidemiology 2(1): 2836. doi:10.33805/2638-8235.113.

25. Mahmud N (2020) PPRC-BIGD Survey: 52\% urban, 36\% rural people take loans during shutdown. DhakaTribune, April 19, 2020

26. Alam G, Shahjamal M, Al-Amin A, Azam M (2014) State of Pharmacy Education in Bangladesh. Tropical Journal of Pharmaceutical Research 12(6): 1106. doi:10.4314/tjpr. v12i6.36.

27. Mazid MA, Rashid MA (2011) Pharmacy Education and Career Opportunities for Pharmacists in Bangladesh. Bangladesh Pharmaceutical Journal 14(1): 1-9.

28. Saha T, Bhuiya RH, Masum ZU, Islam MR, Chowdhury JA (2018) Hospital Pharmacy Management System and Future Development Approaches in Bangladeshi Hospital. Bangladesh Pharmaceutical Journal 20(2): 180-187. doi:10.3329/bpj.v20i2.37883.

29. Jakaria M. Pharmacy practices in Bangladesh. The Independent/Stethoscope, August 03, 2015.

30. Islam MA, Gunaseelan S, Khan SA, Khatun F, Talukder
$R$ (2014) Current challenges in pharmacy education in Bangladesh: A roadmap for the future. Currents in Pharmacy Teaching and Learning 6(5): 730-735. doi:10.1016/j.cptl.2014.05.020.

31. Alam GM, Al-Amin AQ (2014) Role of Pharmacy Education in National Development of Bangladesh: A Scope for Public and Private Sectors. Indian Journal of Pharmaceutical Education and Research 48(4): 11-21. doi:10.5530/ijper.48.4.3.

32. Staff Correspondent (2020) COVID-19 detection hits 7,667, death toll 168 in Bangladesh. NEWAGE Bangladesh, May 01, 2020.

33. Senior Correspondent (2020) Coronavirus cases detected in 11 districts, more than half of them in Dhaka. bdnews24. com, 06.04.2020.

34. Likhon N (2020) Separate plans for corona hotspot districts needed. Bangladesh Post, April 30, 2020.

35. Somoy English Desk (2020) This district luckyly still free from coronavirus. Somoy TV News Portal, April 30, 2020.

36. The Financial Express (2020) Entire Bangladesh is at risk: Health Directorate. National, 16 April, 2020.

37. Masum O (2020) Dhaka hospitals turning away patients with fever, cold needing coronavirus tests. bdnews 24 . com, 19.03.2020.

38. Staff Correspondent (2020) Health minister vows to punish private hospitals for turning away patients. bdnews 24 . com, 03.04.2020.

39. Islam Z, Mollah S (2020) Admission to Hospitals: Patients left in quandary. The Daily Star, 24.03.2020.

40. Akhter F (2020) COVID-19 and healthcare denial. NEWAGE OPINION, 02.04.2020.

41. UNB (2020) DU student 'denied treatment by hospitals' dies. The Financial Express/National, 07.04.2020.

42. Chowdhury T (2020) Poor Bangladeshis being turned away from hospitals. Al Jazeera America News/Bangladesh, 07.04.2020.

43. Tribune Report (2020) Police lock down 52 areas in Dhaka. DhakaTribune, 08.04.2020.

44. Abdullah M (2020) Number of ICU beds insufficient to combat Covid-19 pandemic. DhakaTribune, March 21, 2020 .

45. Hasan K (2020) Healthcare professionals now face the coronavirus wrath. DhakaTribune, March 29, 2020.

46. Azhar S, Hassali MA, Ibrahim MI, Ahmad M, Masood I, Shafie AA (2009) The role of pharmacists in developing countries: the current scenario in Pakistan. Hum Resour Health. 2009;7:54. Published 2009 Jul 13. doi:10.1186/1478-4491-7-54

47. Sakeena MHF, Bennett AA, McLachlan AJ (2018) Enhancing pharmacists' role in developing countries to overcome the challenge of antimicrobial resistance: a narrative review. Antimicrob Resist Infect Control 7: 63 . doi: 10.1186/s13756-018-0351-z.

48. Sakeena MHF, Bennett AA, McLachlan AJ (2019) The Need to Strengthen the Role of the Pharmacist in Sri Lanka: Perspectives. Pharmacy (Basel). 2019;7(2):54. Published 2019 Jun 5. doi:10.3390/pharmacy7020054

49. Rayes IK, Hassali MA, Abduelkarem AR (2015) The 
role of pharmacists in developing countries: The current scenario in the United Arab Emirates. Saudi Pharm J 23(5): 470-474. doi:10.1016/j.jsps.2014.02.004

50. Paul TR, Rahman MA, Biswas M, Rashid M, Islam MAU (2015) Practice of Hospital Pharmacy in Bangladesh: Current Perspective. Bangladesh Pharmaceutical Journal 17(2): 187-192. doi:10.3329/bpj.v17i2.22339.

51. The Pharmaceutical Journal (2009) Development of Hospital Pharmacy in Bangladesh. News \& analysis, June 01, 2009.

52. Chowdhury F, Sturm-Ramirez K, Mamun AA, et al. (2017) Factors driving customers to seek health care from pharmacies for acute respiratory illness and treatment recommendations from drug sellers in Dhaka city, Bangladesh. Patient Prefer Adherence. 2017;11:479-486. Published 2017 Mar 6. doi:10.2147/PPA.S121800

53. AlShayban DM, Naqvi AA, Islam MA, et al. (2020) Patient Satisfaction and Their Willingness to Pay for a Pharmacist Counseling Session in Hospital and Community Pharmacies in Saudi Healthcare Settings. Front Pharmacol 11: 138. Published 2020 Mar 2. doi:10.3389/fphar.2020.00138

54. Khan AN, Khan MU, Shoaib MH, Yousuf RI, Mir SA (2014) Practice nurses and pharmacists: a perspective on the expectation and experience of nurses for future collaboration. Oman Med J 29(4): 271-275. doi:10.5001/ omj.2014.71

55. Nittari G, Pallotta G, Pirillo I, Ricci G, Amenta F (2018) Evaluation of medical prescriptions and off-label use on board ships to improve healthcare quality. Eur Rev Med Pharmacol Sci 22(13): 4392-4400. doi: 10.26355/ eurrev_201807_15439.

56. Safitrih L, Perwitasari DA, Ndoen N, Dandan KL (2019) Health Workers' Perceptions and Expectations of the Role of the Pharmacist in Emergency Units: A Qualitative Study in Kupang, Indonesia. Pharmacy (Basel) 7(1): 31. Published 2019 Mar 22. doi:10.3390/pharmacy7010031

57. Chevalier B, Neville HL, Thompson K, Nodwell L, MacNeil M (2016) Health Care Professionals' Opinions and Expectations of Clinical Pharmacy Services on a Surgical Ward. Can J Hosp Pharm 69(6): 439-448. doi:10.4212/cjhp.v69i6.1606

58. Schneider PJ(2013) Evaluating the impact of telepharmacy. Am J Health Syst Pharm. 2013 Dec 1;70(23):2130-5. doi: 10.2146/ajhp130138.

59. Watanabe JH, McInnis T, Hirsch JD (2018) Cost of Prescription Drug-Related Morbidity and Mortality. Ann Pharmacother 52(9): 829-837. doi: $10.1177 / 1060028018765159$.

60. Littauer SL, Dixon DL, Mishra VK, Sisson EM, Salgado TM (2017) Pharmacists providing care in the outpatient setting through telemedicine models: a narrative review. Pharm Pract (Granada) 15(4): 1134. doi:10.18549/ PharmPract.2017.04.1134

61. Langarizadeh M, Tabatabaei MS, Tavakol K, Naghipour M, Rostami A, Moghbeli F (2017) Telemental Health Care, an Effective Alternative to Conventional Mental Care: a Systematic Review. Acta Inform Med 25(4): 240-
246. doi:10.5455/aim.2017.25.240-246

62. Zheng SQ, Yang L, Zhou PX, Li HB, Liu F, Zhao RS (2020) Recommendations and guidance for providing pharmaceutical care services during COVID-19 pandemic: A China perspective. Res Social Adm Pharm. 2020;. doi:10.1016/j.sapharm.2020.03.012

63. Carico RR Jr, Sheppard J, Thomas CB (2020) Community pharmacists and communication in the time of COVID-19: Applying the health belief model [published online ahead of print, 2020 Mar 26]. Res Social Adm Pharm S15517411(20)30293-X. doi:10.1016/j.sapharm.2020.03.017

64. Cadogan CA, Hughes CM (2020) On the frontline against COVID-19: Community pharmacists' contribution during a public health crisis. Res Social Adm Pharm. 2020 Mar 31. pii: S1551-7411(20)30292-8. doi: 10.1016/j. sapharm.2020.03.015.

65. Miller S, Patel N, Vadala T, Abrons J, Cerulli J (2012) Defining the pharmacist role in the pandemic outbreak of novel H1N1 influenza. J Am Pharm Assoc (2003) 52(6): 763-767. doi: 10.1331/JAPhA.2012.11003.

66. Sorwar G, Rahamn MM, Uddin R, Hoque MR (2016) Cost and Time Effectiveness Analysis of a Telemedicine Service in Bangladesh. Stud Health Technol Inform 231: 127-134.

67. Vassallo DJ, Swinfen P, Swinfen R, Wootton R (2001) Experience with a low-cost telemedicine system in three developing countries. J Telemed Telecare 7 Suppl 1: 5658.

68. Rahman MS, Shuvo MH (2015) International Journal of Innovative Research in Science, Engineering and Technology (IJIRSET) 4(6): 4810-4822. doi:10.15680/ IJIRSET.2015.0406131. Available In: http://www.ijirset. com/upload/2015/june/131_Advancement.pdf

69. Nessa A, Ameen MA, Ullah S, Kwak KS (2008) Applicability of Telemedicine in Bangladesh: Current Status and Future Prospects. 2008 Third International Conference on Convergence and Hybrid Information Technology. 2008: 138-145. doi:10.1109/iccit.2008.236.

70. Khatun F, Heywood AE, Hanifi SMA, Rahman MS, Ray PK, Liaw ST, Bhuiya A (2017) Gender differentials in readiness and use of mHealth services in a rural area of Bangladesh. BMC Health Serv Res 17(1): 573. doi: 10.1186/s12913-017-2523-6.

71. Ahmed T, Lucas H, Khan AS, Islam R, Bhuiya A, Iqbal $M$ (2014) eHealth and mHealth initiatives in Bangladesh: a scoping study. BMC Health Serv Res 14: 260. doi: 10.1186/1472-6963-14-260.

72. Hossain MN, Okajima H, Kitaoka H, Yokota F, Ahmed A (2018) eHealth Consumer Behavior. International Series on Computer Entertainment and Media Technology Behavior Engineering and Applications. 2018: 129-147. doi:10.1007/978-3-319-76430-6_6.

73. Star Online Report. For emergency, dial 999. The Daily Star, December 12, 2017.

74. Alif A (2020) Coronavirus: Frustration rising over inadequate hotline services. DhakaTribune, March 19, 2020.

75. Baldoni S, Amenta F, Ricci G (2019) Telepharmacy 
Services: Present Status and Future Perspectives: A Review. Medicina (Kaunas) 55(7): 327. Published 2019 Jul 1. doi:10.3390/medicina55070327

76. Poudel A, Nissen LM. Telepharmacy (2016) : a pharmacist's perspective on the clinical benefits and challenges [published correction appears in Integr Pharm Res Pract. 2016 Nov 10;5:83]. Integr Pharm Res Pract 5: 75-82. Published 2016 Oct 26. doi:10.2147/IPRP. S101685

77. Mohiuddin AK. Clinical Pharmacists in Chronic Care. Global Journal of Medical Research. 2019:1-60. doi:10.34257/gjmrkvol19is8pg1.

78. Alexander E, Butler CD, Darr A, Jenkins MT, Long RD, Shipman CJ, Stratton TP (2017) ASHP Statement on Telepharmacy. Am J Health Syst Pharm 74(9): e236-e241. doi: 10.2146/ajhp170039.

79. Raposo VL. Telemedicine (2016) : The legal framework (or the lack of it) in Europe. GMS Health Technol Assess. 2016;12:Doc03. Published 2016 Aug 16. doi:10.3205/ hta000126

80. Crico C, Renzi C, Graf N, et al. (2018) mHealth and telemedicine apps: in search of a common regulation. Ecancermedicalscience 12: 853. Published 2018 Jul 11. doi:10.3332/ecancer.2018.853

81. Cimperman M, Brenčič MM, Trkman P, Stanonik Mde L (2013) Older adults' perceptions of home telehealth services. Telemed J E Health 19(10): 786-790. doi:10.1089/tmj.2012.0272

82. van Houwelingen CT, Ettema RG, Antonietti MG, Kort HS (2018) Understanding Older People's Readiness for Receiving Telehealth: Mixed-Method Study. J Med Internet Res 20(4): e123. Published 2018 Apr 6. doi:10.2196/jmir.8407

83. Evans J, Papadopoulos A, Silvers CT, et al. (2016) Remote Health Monitoring for Older Adults and Those with Heart Failure: Adherence and System Usability. Telemed J E Health 22(6): 480-488. doi:10.1089/tmj.2015.0140

84. Goodridge D, Marciniuk D (2016) Rural and remote care: Overcoming the challenges of distance. Chron Respir Dis 13(2): 192-203. doi:10.1177/1479972316633414

85. Whitten P, Holtz B, Laplante C. Telemedicine (2010): What have we learned?. Appl Clin Inform 1(2): 132-141. Published 2010 May 5. doi:10.4338/ACI-2009-12-R-0020

86. Iftikhar S, Saqib A, Sarwar MR, Sarfraz M, Arafat M, Shoaib Q-U-A (2019) Capacity and willingness to use information technology for managing chronic diseases among patients: A cross-sectional study in Lahore, Pakistan. Plos One. 2019;14(1). doi:10.1371/journal. pone.0209654.

87. Zhou L, Thieret R, Watzlaf V, Dealmeida D, Parmanto B (2019) A Telehealth Privacy and Security Self-Assessment Questionnaire for Telehealth Providers: Development and Validation. Int J Telerehabil 11(1): 3-14. Published 2019 Jun 12. doi:10.5195/ijt.2019.6276

88. Smith KA, Zhou L, Watzlaf VJM (2017) User Authentication in Smartphones for Telehealth. Int J Telerehabil 9(2): 3-12. Published 2017 Nov 20. doi:10.5195/ijt.2017.6226
89. Hale TM, Kvedar JC (2014) Privacy and Security Concerns in Telehealth. AMA Journal of Ethics 16(12): 981-985. doi:10.1001/virtualmentor.2014.16.12.jdsc1-1412.

90. Arora S, Yttri J, Nilse W (2014) Privacy and Security in Mobile Health (mHealth) Research. Alcohol Res 36(1): 143-151.

91. Sankaranarayanan J, Murante LJ, Moffett LM (2014) A retrospective evaluation of remote pharmacist interventions in a telepharmacy service model using a conceptual framework. Telemed J E Health 20(10): 893901. doi:10.1089/tmj.2013.0362

92. Nittari G, Khuman R, Baldoni S, Pallotta G, Battineni G, Sirignano A, Amenta F, Ricci G (2020) Telemedicine Practice: Review of the Current Ethical and Legal Challenges. Telemed J E Health. 2020 Feb 12. doi: $10.1089 /$ tmj.2019.0158.

93. Koumaditis K, Themistocleous M, Morabito V (2013) New Trends in Healthcare Information Systems (HIS) Integration. Handbook of Research on ICTs for HumanCentered Healthcare and Social Care Services. 2013: 784801. doi:10.4018/978-1-4666-3986-7.ch041.

94. Steckler T (2016) Telepharmacy: Controversy and Promise. J Pharm Technol 32(6): 227-229. doi:10.1177/8755122516670415

95. Marcoux RM, Vogenberg FR (2016) Telehealth: Applications From a Legal and Regulatory Perspective. P T 41(9): 567-570.

96. Bashshur RL, Shannon G, Krupinski EA, Grigsby J (2013) Sustaining and realizing the promise of telemedicine. Telemed J E Health 19(5): 339-345. doi:10.1089/ tmj.2012.0282

97. Zhao M, Hamadi H, Haley DR, Xu J, White-Williams C, Park S (2020) Telehealth: Advances in Alternative Payment Models. Telemedicine and e-Health. 2020. doi:10.1089/tmj.2019.0294.

98. Gilman M, Stensland J (2013) Telehealth and Medicare: payment policy, current use, and prospects for growth. Medicare Medicaid Res Rev. 2013;3(4):mmrr.003.04.a04. Published 2013 Dec 4. doi:10.5600/mmrr.003.04.a04

99. Osterweil D (2009) Telehealth Is Ready, Payment System Isnt. Caring for the Ages. 2009;10(11):17. doi:10.1016/ s1526-4114(09)60305-x.

Copyright: (C2020 Abdul Kader Mohiuddin. This is an open-access article distributed under the terms of the Creative Commons Attribution License, which permits unrestricted use, distribution, and reproduction in any medium, provided the original author and source are credited. 